\title{
Uncertainty estimation of biomass expansion factors for Norway spruce in the Czech Republic
}

\author{
Aleksi LEHTONEN $^{\mathrm{a} *}$, Emil CIENCIALA ${ }^{\mathrm{b}}$, Fedor TATARINOV ${ }^{\mathrm{b}}$, Raisa MäKIPÄÄ \\ ${ }^{a}$ Finnish Forest Research Institute, P.O. Box 18, 01301 Vantaa, Finland \\ ${ }^{\mathrm{b}}$ Institute of Forest Ecosystem Research (IFER), 25401 Jílové u Prahy 1544, Czech Republic
}

(Received 12 April 2006; accepted 25 August 2006)

\begin{abstract}
Nation wide estimates of the changes in forest biomass are needed for the greenhouse gas (GHG) reporting under the Climate Convention. The bases for national GHG reporting concerning forest sector are the national forest inventory (NFI) programmes. Since these programmes were mostly established for monitoring of timber resources, one of the current challenges for the NFIs is the development of methodology, such as biomass expansion factors $(B E F s)$. The methodology for carbon stock change estimation should be transparent and verifiable, but this demand is not currently met due to the fact that the source data and uncertainty in the applied $B E F s$ are not known. Here we developed $B E F s$ with uncertainty estimation applicable to stand wise inventory of Norway spruce forests in the Czech Republic. BEFs were constructed, based on tree wise data from permanent research plots, by applying biomass and volume models to tree-level data. These BEFs were age-dependent and their uncertainty was sensitive to the dependencies among errors. Most of the uncertainty in the BEFs was due to uncertainty in the biomass and volume models applied.
\end{abstract}

biomass expansion factor / Monte Carlo simulation / greenhouse gas inventory / national forest inventory

Résumé - Incertitudes pour l'estimation des facteurs d'expansion de la biomasse chez l'épicéa en République tchèque. Les estimations de la biomasse des forêts servent à évaluer les effets des changements climatiques et à dresser des rapports internationaux. En foresterie, les rapports nationaux sur les gaz à effet de serre (GES) sont basés sur l'inventaire forestier national. L'objectif premier de cet inventaire étant la prévision des ressources de bois brut, l'inventaire des GES appelle des méthodes de prévision basée sur les facteurs d'expansion de la biomasse. Les méthodes d'estimation des GES devraient être transparentes et vérifiables - objectif souvent non atteint parce que l'origine et l'incertitude des facteurs d'expansion de la biomasse ne sont pas connues. Dans cette étude nous avons développé des facteurs d'expansion de la biomasse des forêts de sapin dans la République tchèque et calculé l'incertitude de ceux-ci. Les facteurs ont été estimés en fonction des mesures au niveau de l'arbre dans des zones d'échantillonnage permanentes et de l'application des modèles de volume et de biomasse. Ces facteurs d'expansion étaient dépendants de l'âge et leur incertitude sensible aux corrélations entre les erreurs. L'incertitude des facteurs d'expansion était principalement due aux modèles de biomasse et de volume appliqués.

facteur d'expansion de la biomasse / simulation Monte Carlo / inventaire des gaz à effet de serre / inventaire forestier national

\section{INTRODUCTION}

The recent adoption of new methodological guidance in the sector land-use change and forestry [7] as well as the recent adoption of the Kyoto Protocol require revision of the national emission inventory systems that have so far been applied for reporting under the Climate Convention (United Nations Framework Convention on Climate Change, UNFCCC). The specific focus must be on the category of forests, which in many Annex I countries is one of the key categories. It has already been shown that the uncertainty in the emissions and sinks of these key categories is substantial $[17,19]$. The Intergovernmental Panel on Climate Change (IPCC) [7] suggests that higher tier methods should be used to minimize the uncertainty in carbon stock change assessment, but often the actual uncertainty estimates for emissions and sinks in the forest sec-

\footnotetext{
*Corresponding author: aleksi.lehtonen@metla.fi
}

tor are lacking. This also applies to the conditions in the Czech Republic. The source data used for the national reporting of carbon stocks and stock changes have been based on the data obtained from forest management plans (FMPs). These data constitute stand-level aggregated information on species composition, areas, mean stand height, mean stand diameter and merchantable stand volume reported by age-classes. Greenhouse gas (GHG) reporting under IPCC guidance [7] encompasses total carbon stock change by five basic components that include aboveground biomass, belowground biomass, litter, deadwood and soil. Among these pools the key component to be reported is biomass, due to its immediate reactions on human interventions such as logging and silviculture. Revision of the GHG inventory system requires that suitable biomass expansion factors $(B E F s)$, with uncertainty estimation are estimated (here $B E F$ refers to the ratio between aboveground biomass and merchantable volume). Moreover, the biomass 

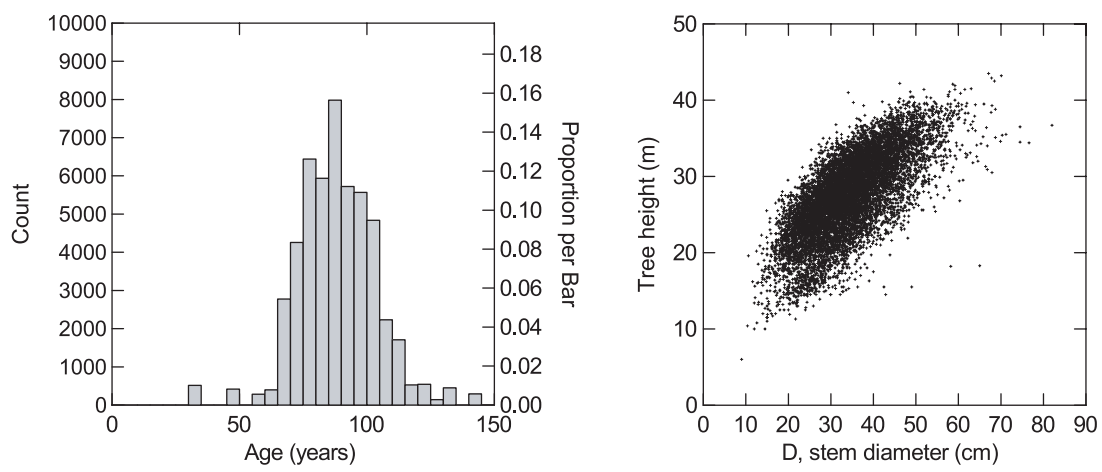

Figure 1. Left frequency of the sampled spruce trees $(n=51035)$ by age-class intervals of 5 years. Right: tree height vs. tree diameter for the measured trees $(n=10100)$.

estimates at national level can vary heavily between different studies due to inappropriate biomass estimation methods, see e.g. for Russia [23]. Recently, the aboveground biomass of forests in the Czech Republic was estimated with constant $B E F s$ based either on national studies or IPCC defaults [2,7], similarly as in many other countries $[14,27]$, although it is known that during stand development the relative proportions of canopy and stem in the total mass vary [22]. In the United Kingdom, Levy et al. [13] showed that tree-level BEFs were dependent on tree height, while Fang et al. [5] modelled BEFs as a function of stem volume in China. In Finland Lehtonen et al. [12] modelled stand-level BEFs as a function of stand age, and found that the relationship was rather weak for total biomass, but stronger for individual biomass components, especially for foliage and branches.

In addition to being constant, the uncertainty in these previously used conversion factors is not known, while there are studies that indicate relatively high levels of uncertainty for biomass estimation $[8,17,28]$. Levy et al. [13] showed that the expansion factor $(E F)$ for Norway spruce, Picea abies (L.) Karst varied between 1.2 and 2, with a mean of 1.546 and standard deviation of 0.19. Lehtonen et al. [12] found that the RSE (relative standard error) of BEFs for Norway spruce sites in Finland varied between $3 \%$ and $21 \%$ and was highest in those age-classes with few observations. Currently the uncertainty in conversion from tree volume to carbon content at national level is not known, but is needed for reporting the uncertainties of GHG inventory. Most of the reported uncertainty estimates of carbon stock change in forests are based on expert judgement $[6,7]$ or on collections of published biomass measurements [24].

Two main limitations of the currently applied BEFs are (i) that they do not utilize the available national source data and (ii) that no uncertainty estimate is performed. Here these issues are tackled with the use of permanent research plot data, published biomass equations and Monte Carlo error propagation including model and measurement errors. The aim of this paper was to present an approach to estimate stand-level BEFs, both by age-classes (reflecting the available format of source data) and as a single value and to analyse the associated $B E F$ uncertainty for Norway spruce stands in the conditions of the Czech Republic.

\section{MATERIAL AND METHODS}

\subsection{Material}

A nation wide network of permanent research plots (PRPs) established in 1960s and complemented by some additional research plot networks during the time was used in this study. The measurements used for formulation of BEFs were taken between 1996 and 2003 and represent current stand structures and growth conditions.

All plots containing Norway spruce were evaluated to include only those in which the percentage of its basal area was at least $95 \%$. This sub sample of data used for the analysis constituted 325 plots distributed across the country, including 264 unique plots and 61 cases of the repeated (second) measurement campaign performed about 5 years after the previous campaign. These 61 plots were included twice in the analysis as independent observations. An average of 189 trees were measured (min. 54, max. 428) on each selected plot and measuring occasion (year), and the sizes of the plots varied between 346 and $9000 \mathrm{~m}^{2}$ (due to different origin of the plot network) including altogether 51035 sampled trees (Fig. 1); each plot had the same weight in the analysis. The dataset covered stand ages of 32143 years, with a mean age of 88 years (Fig. 1). On each plot, every tree was measured for diameter at breast height $(D)$, while approximately every fifth tree was measured for tree height $(H)$. The range of stand dominant heights was 13.3 to $36.3 \mathrm{~m}$, tree density varied between 120 and 1336 trees/ha and stand basal area was 14.8-73.1 $\mathrm{m}^{2} \mathrm{ha}^{-1}$ with a mean of $45.9 \mathrm{~m}^{2} \mathrm{ha}^{-1}$.

\subsection{Estimating biomass expansion factors}

Here the $B E F$ was defined as,

$$
B E F=\frac{W}{V_{m}}
$$

where the index $W(\mathrm{Mg})$ denotes the aboveground biomass (including: foliage, living branches, dead branches and stem over bark), while $V_{m}\left(\mathrm{~m}^{3}\right)$ is the merchantable tree wood volume under the bark. Merchantable volume in Czech forestry is generally restricted to tree stem and branch components with top diameter above $7 \mathrm{~cm}$. While for other tree species the proportion of merchantable branch wood may be significant, in the case of spruce the above-noted dimension threshold applies basically to stem only. For computation of stand-level $B E F s, W$ and $V_{m}$ were the sums of the estimated tree-level biomass 
Table I. Parameter estimates for the fixed part of the tree height model.

\begin{tabular}{lccc}
\hline Parameter & Estimate & Standard error & $t$-value \\
\hline$a$ & 3.609 & 0.011 & 328.85 \\
$b$ & -11.368 & 0.183 & -61.97 \\
\hline
\end{tabular}

and the merchantable volumes for trees measured in the given sample plot. Thus, the $B E F$ is expressed as $\mathrm{Mg} \mathrm{m}^{-3}$ and represents both conversion to dry mass and expansion to include bark, tree tops and canopy when applied to known merchantable wood volumes [25].

Tree-level measurements from each plot were used to estimate a $B E F$ value for each site. The diameter at breast height $(D)$ and tree height $(H)$ were used in the biomass and volume models. Since only approximately every fifth tree from each plot was measured for $H$, the remaining tree heights were modelled as a function of $D$ by a linear mixed model to enable use of biomass and volume equations that are based on both $D$ and $H$.

$$
\ln (H-1.3)=a+b \times \frac{1}{D}+A_{i}+B_{i} \times \frac{1}{D}+\varepsilon_{i}
$$

where intercept $a$ and slope $b$ were fixed parameters, while $A_{i}$ and $B_{i}$ were random parameters with zero expectations that were allowed to vary according to plot $i$ for parameter estimates and their standard errors, see Table I. The fixed and random parameters were estimated with the mixed model in SAS $[16,21]$. The bias correction was ignored after realizing that the residuals of the measured heights showed a mean of $4.4 \mathrm{~cm}$ (and means varied between 1 and $30 \mathrm{~cm}$ when data was grouped into 20 height classes with $2 \mathrm{~m}$ interval), indicating that the height model estimates were nearly unbiased on an arithmetic scale. For prediction of the tree height plot specific random parameters were used.

The estimate for $V_{m}$ was calculated following the national volume equations as published by [20]. The specific equation used for $V_{m}$ of spruce is given in the form

$$
V_{m}=a 1 \times(D+1)^{a 2} \times H^{a 3}-a 4 \times(D+1)^{a 5} \times H^{a 6}+\varepsilon
$$

where $H$ is the height and $D$ the diameter, while $a 1, a 2, a 3, a 4, a 5$ and $a 6$ are parameters set to $3.1989 \times 10^{-5}, 1.8465,1.1474,8.2905 \times 10^{-3}$, -1.0204 and 0.8961 , respectively [20].

The estimate of aboveground biomass $(W)$ was calculated as a sum of estimates for individual components (foliage, branches, dead branches and stem) using the mixed model equations (Eq. (4)) from Wirth et al. [28]. These equations were applied, utilizing $D, H$ and $A$ (age) as independent variables, excluding branches that were based only on $D$ and $H$ (for the biomass models applied here see Tables III and IV in Wirth et al. [28]). The used equations had following AIC and $R M S E$ values, for foliage $(462.2,0.338)$, for branches $(474.9$, $0.395)$, for dry branches $(342.4,0.481)$ and for stem $(-300.6,0.108)$ [28]. Generally, the biomass functions followed the formulation below,

$$
\ln W_{c}=b_{0}+b_{1} \times \ln D+b_{2} \times \ln H+b_{3} \times \ln A+\varepsilon
$$

but noting that additional terms of predictors were possible, e.g. power of the logarithm of diameter. Here $b_{0}-b_{3}$ are parameters, while $W_{c}$ indicates the biomass of a component $\mathrm{c}$, according to Wirth et al. [28].

To obtain estimates for plot-level $B E F$ s, aboveground biomass and merchantable volume of all trees were summed at the plot level. Plotlevel $B E F$ s were modelled as a function of stand age $(A)$ and the estimated plot-level $B E F$ values and their relationship to stand age were approximated using the same functional form as in Lehtonen et al. [12], where

$$
B E F=a+b \cdot \mathrm{e}^{-0.01 \cdot A}+\varepsilon
$$

$B E F$ was the biomass expansion factor for aboveground biomass, while $a$ and $b$ were parameters. Since the observations for young stands were scarce and uncertain, the parameterization of Equation (5) was limited to data for stands older than 30 years. Similarly, the upper age limit for functional dependence was considered to be 165 years, which corresponds to the upper age-class of data from the FMPs that are traditionally collated in the country's forestry database.

\subsection{Uncertainty estimation for $B E F s$}

The estimate of uncertainty in $B E F s$ results from two main sources here: (i) measurement errors of individual input variables and (ii) prediction errors of both biomass and stem volume equations (Tab. II). The uncertainty estimation was performed, using a Monte Carlo simulation with SAS software [21].

The assumption of measurement errors of diameter $(D)$ and height $(H)$ were based on the Finnish field survey of biomass data by the national tree research $[9,18]$. Both $D$ and $H$ were measured before ( $D$ with one calliper measurement and $H$ by hypsometer) and after felling and stem analysis ( $D$ with two calliper measurements and $H$ by tape) and the differences were considered as a measurement error. The quantity of error and its distribution were estimated, assuming that the measurement error of the Finnish field survey team equalled that of their Czech colleagues (Tab. II). The measurement error of tree height was slightly dependent on tree height and therefore was quantified by the height classes (Tab. II). The uncertainty in stand age was included and was assumed to have an RSE of $15 \%$ based on a study by Eid [4]. For trees lacking measurements of $H$, height was modelled, and the prediction error of the mixed model (Eq. (2)) was used [21]. The errors for biomass were estimated based on the covariance matrices and reported residual errors from Wirth et al. [28] (obtained from ftp://panorama.bgc-jena.mpg.de/pub/science/cwirth/). The uncertainty in the stem volume model was not known and thereafter the RSEs of the individual predictions for stem volume were assumed to be $10 \%$, random between trees and normally distributed. This assumption was based on the work of Laasasenaho [10], who derived RSEs of 7-8\% for prediction of stem volume of Scots pine, Pinus sylvestris L. in Finland with selected values of $D$ and $H$.

Each simulation round was started by simulating the values of $D$ and $H$ for each tree. Initial data on $D$ and $H$ were taken from measurements at the plots. The measured values for $D$ and $H$ were simulated with the measurement errors and drawn random number from a standardized normal distribution. After simulating $D$ and $H$, a model for the $H-D$ relationship was built to estimate $H$ for trees lacking measurements for this variable. A linear mixed model [16] was estimated separately during each simulation round (Eq. (2)), in addition to that modelled heights were simulated with estimated $H$ and its standard error (meaning that also modelled heights had an uncertainty that was used in simulations)

The estimated values for $D$ and $H$ (simulated with uncertainty) were used to estimate the values for merchantable stem volume (Eq. (3)) and for aboveground biomass (Eq. (4)). The error in each biomass component was estimated, based on simulated parameter values that fulfil variance-covariance matrices from Wirth et al. [28]. 
Table II. Standard errors (SE) and relative standard errors (RSE) of input variables and prediction errors of used models and their distributions. Note that the RSEs of tree height and biomass are dependent on tree dimensions.

\begin{tabular}{|c|c|c|c|c|c|}
\hline Input variable or model & $\mathrm{SE}(\mathrm{cm}) \mathrm{min}$. & $\mathrm{SE}(\mathrm{cm})$ median & $\mathrm{SE}(\mathrm{cm}) \max$. & Distribution & Type of error \\
\hline$D$ (stem diameter) & 0.4 & 0.4 & 0.4 & Normal & Measurement \\
\hline$H$, measured $(<10 \mathrm{~m})$ & 40 & 40 & 40 & Normal & Measurement \\
\hline$H$, measured $(10-15 m)$ & 50 & 50 & 50 & Normal & Measurement \\
\hline \multirow[t]{2}{*}{$H$, measured $(>15 \mathrm{~m})$} & 60 & 60 & 60 & Normal & Measurement \\
\hline & $\mathrm{RSE}(\%) \min$ & RSE (\%) average & $\mathrm{RSE}(\%) \max$ & Distribution & Type of error \\
\hline$H$, modelled & 1 & 4 & 36 & Lognormal & Model \\
\hline Stand age & 15 & 15 & 15 & Normal & Measurement \\
\hline Biomass, foliage & 32 & 48 & 116 & Lognormal & Model \\
\hline Biomass, branches & 32 & 42 & 75 & Lognormal & Model \\
\hline Biomass, dead branches & 33 & 61 & 170 & Lognormal & Model \\
\hline Biomass, stem & 11 & 14 & 43 & Lognormal & Model \\
\hline Stem volume & 10 & 10 & 10 & Normal & Model \\
\hline
\end{tabular}

Table III. Results of regression of $B E F$ on stand age (Eq. (5)) for Norway spruce in the Czech Republic.

\begin{tabular}{lccccccc}
\hline Parameter & Estimate & Std. err. & $t$-value & Confidence interval & $N$ & $R^{2}$ \\
\hline$a$ & 0.4971 & 0.0075 & 66.7 & 0.4824 & 0.5118 & & \\
$b$ & 0.1996 & 0.0177 & 11.3 & 0.1649 & 0.2344 & & 0.28 \\
$b$ & &
\end{tabular}

In addition to the parameter uncertainty also the residual component of uncertainty was included. The same parameter values were used for the biomass estimation for trees during each simulation round, while random error varied between trees. The errors in the biomass models were distributed normally on a logarithmic scale. The estimates of merchantable volume were simulated with the assumed model error (which was random between trees).

Tree biomass and merchantable volume was summed at the plot level; thereafter the $B E F$ was derived for each plot by dividing the total biomass with the total merchantable volume. Each simulation round produced a $B E F$ value for each plot, and after all 1000 rounds the probability distribution of $B E F$ was determined and $95 \%$ confidence intervals quantified. These $B E F$ values were also plotted against stand age, which was estimated during the field cruise (Tab. III). The estimated values for stand age were simulated according to the assumed measurement error (RSE of 15\%) and a random number. The simulations were performed for all 325 plots with 1000 rounds to obtain the error distribution of the $B E F$ (confidence intervals of $B E F s$ stabilized after few hundreds of simulation rounds, therefore 1000 rounds were used).

The simulations were performed for four error correlation schemes, in which the residual errors of the biomass and volume models were introduced with varying degrees of intraplot dependency among trees (Tab. IV). It is known that the clustered structure of data (trees and plots) introduce dependencies between errors and that the residual errors in trees from the same plot correlate (e.g. [11]), therefore the simulations were performed for four error correlation schemes ( $n=1000$ for each scheme). We assumed that the residual errors between the estimated tree components (foliage mass, mass of living branches, mass of dead branches, stem mass and merchantable stem volume) were positively correlated $[3,28]$. The dependencies between residual errors of modelled tree components from the same plot were obtained by varying the use of random numbers throughout the simulations. The intraplot dependency between trees and their
Table IV. Assumptions of the percentage of variance that do not vary between trees (applied with residual errors of biomass- and volume models) from the same plot (\%) and the resulting median and percentiles for $B E F s$.

\begin{tabular}{lcccc}
\hline Correlation scheme & 0 & 1 & 2 & 3 \\
\hline $\begin{array}{l}\text { \% of constant intraplot variance between } \\
\text { residual errors of model }\end{array}$ & 0 & 100 & 60 & 40 \\
\hline $97.5 \%$ & 0.68 & 0.71 & 0.71 & 0.70 \\
Median $B E F$ & 0.57 & 0.57 & 0.57 & 0.57 \\
$2.5 \%$ & 0.48 & 0.47 & 0.47 & 0.47 \\
\hline
\end{tabular}

model errors was introduced by applying the weighted mean of random numbers (Eq. (6)), in which a proportion was modified with the same random number for trees in the same plot, while the remaining fluctuated among trees and weights were chosen according to the degree of intraplot dependency (Eq. (6) and Tab. IV).

Weighted means of these random numbers were used during the simulations and the weights were dependent on the assumed intraplot variances (Tab. IV). A random number with a normal distribution and expected mean of zero and variance of $1\left(r_{i j}\right)$ was obtained for tree $i$ from plot $j$ by a weighted mean of random numbers $r_{i}$ and $r_{j}$ that had zero as the expected value and 1 for the variance,

$$
r_{i j}=\frac{1}{\sqrt{w_{i}^{2}+w_{j}^{2}}} \times\left[w_{i} \times r_{i}+w_{j} \times r_{j}\right]
$$

where $w_{j}^{2}$ is the proportion of variance explained by plot factor, while $1-w_{j}^{2}$ is the part of the variance that fluctuates between trees and the sum of weights $w_{i}$ and $w_{j}$ is equal to 1 (Eq. (6)).

The contribution of various errors to the overall uncertainty in the $B E F$ was studied using sensitivity analysis, in which the input errors were individually set to zero. The uncertainties in stand age, measurements (both $D$ and $H$ ), stem volume model and biomass model were removed individually, and the resulting output distributions examined. The situation in which both the biomass model and volume model errors were set to zero was also studied. 


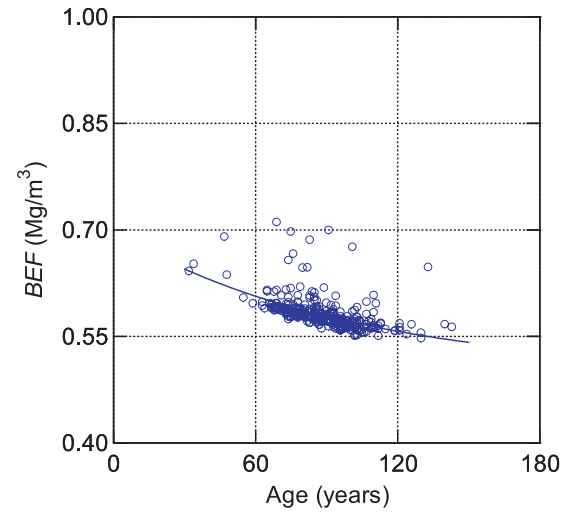

Figure 2. BEFs for Norway spruce as a function of stand age with predicted model (Tab. III).

\section{RESULTS}

\subsection{Biomass expansion factors}

The BEFs for Norway spruce were slightly age-dependent and the ratio of aboveground biomass to merchantable volume decreased with increasing stand age (Fig. 2). The proportion of variance of the $B E F$ that was explained by the stand age was low $\left(r^{2}=0.28\right)$. The parameters $a$ and $b$ of Equation (5) were estimated as $0.501( \pm 0.015)$ and $0.193( \pm 0.034)$ $\mathrm{Mg} / \mathrm{m}^{3}$, respectively. This implies that the relationship of $B E F$ to stand age was rather weak, but significant (here excluding sites younger than 30 years).

\subsection{Uncertainty estimation}

The uncertainty in the $B E F$ was affected by the intraplot residual error dependency (i.e. the dependency between residual errors of the biomass and volume models) (Fig. 3). The $B E F$ showed $95 \%$ confidence intervals of 0.48 and 0.68 in the independent errors and 0.47 and 0.71 with full correlation between the biomass and volume model residual errors at the plot level. The confidence intervals were 0.47 and 0.71 when the percentage of constant intraplot residual variance between the model errors was reduced to $60 \%$, while being 0.47 and 0.70 with $40 \%$ (Fig. 3 and Tab. IV).

The confidence intervals for $B E F s$ by age-classes were also widest with full correlation and narrowed when moved from $60 \%$ to $40 \%$ intraplot residual variance and finally to independent errors (Fig. 4 and Tab. V). The upper bounds of $95 \%$ confidence intervals were 17-30\% for independent errors and 23$33 \%$ for full correlation higher than medians. These error distributions were asymmetrical and wider between median and the $97.5 \%$ percentile than between the $2.5 \%$ percentile and the median, due to lognormal distribution of the biomass model errors.

Sensitivity analysis with $60 \%$ of constant intraplot residual variance showed that the best way to increase the precision of BEFs would be the reduction in error of the biomass and volume models (Fig. 5). Examining the sensitivity in uncertainty of the $B E F$ by ignoring the uncertainty in stand age increased the error in young and old age-classes. Having the uncertainty in stand age included with the Monte Carlo simulation widened the overall age distribution of sites and thus reduced the uncertainty in individual age-classes (Fig. 5).

\section{DISCUSSION}

In the present study, the median value of the aboveground $B E F$ for Norway spruce was between 0.569 and $0.574 \mathrm{Mg}$ $\mathrm{m}^{-3}$, while a study in Finland [12] reports $0.64 \mathrm{Mg} \mathrm{m}^{-3}$ for the same species. The difference between reported BEFs is consistent with the findings of Wirth et al. [28], who reported that Norway spruce in the study of Marklund [15] showed relatively more biomass in their canopy compared with Norway spruce in central Europe. Furthermore, it must be noted that the $B E F$ for Finland was based on stem volume over the bark [12], while here merchantable volume was used. Levy et al. [13] showed that the $E F$, i.e. a dimensionless ratio of total aboveground volume to the merchantable volume, for Norway spruce in the UK was 1.546 , assuming that a wood density of $0.40 \mathrm{Mg} \mathrm{m}^{-3}$ [7] results in $0.62 \mathrm{Mg} \mathrm{m}^{-3}$ as a $B E F$ with comparable units, which is somewhat higher than the values obtained here. The BEFs developed here present a solid basis for carbon stock change estimation for forests in the Czech Republic compared with previous methods [2], in which $18 \mathrm{Mg} \mathrm{ha}^{-1}$ was assumed for branch and foliage biomass of all forest sites despite the varying values for stand age and stocking densities.

The decreasing rate of the $B E F$ as a function of age was steeper in the Czech Republic than in Finland according to Lehtonen et al. [12], parameter $b$ being 0.13 for Finland and 0.2 here (Eq. (5) and Tab. III), although noting that the estimated $95 \%$ confidence intervals by age-classes were relatively wide. Thus, the $B E F s$ derived for different age-classes showed a decreasing trend with stand age that can be accounted for when the carbon stock of biomass is estimated, especially if the age-class structure of forests is changing (Fig. 4).

The results of the study underline the importance of the assessment of correlation between errors, which had an impact on overall $B E F$ uncertainty (Fig. 4). The easiest way to conduct a Monte Carlo analysis is to assume the presence of independent errors, while previous studies have shown that the residual errors in the biomass and stem volume models do correlate $[3,28]$. The results of this study also show that the inclusion of these error correlations at the plot level increases the error bounds and that with full correlation between model errors at the plot level the sample size is reduced from more than 50000 units (trees) to 325 units (plots), leading to wider error bounds. Here the intra-plot correlation between residual errors were assumed, while in optimal situation one would have biomass- and volume data measured from same trees, which would enable proper analysis of these correlations.

Wirth et al. [28] showed that the prediction errors of biomass models for the aboveground components correlated positively and moderately (footnote in Tab. VII in [28]). It 

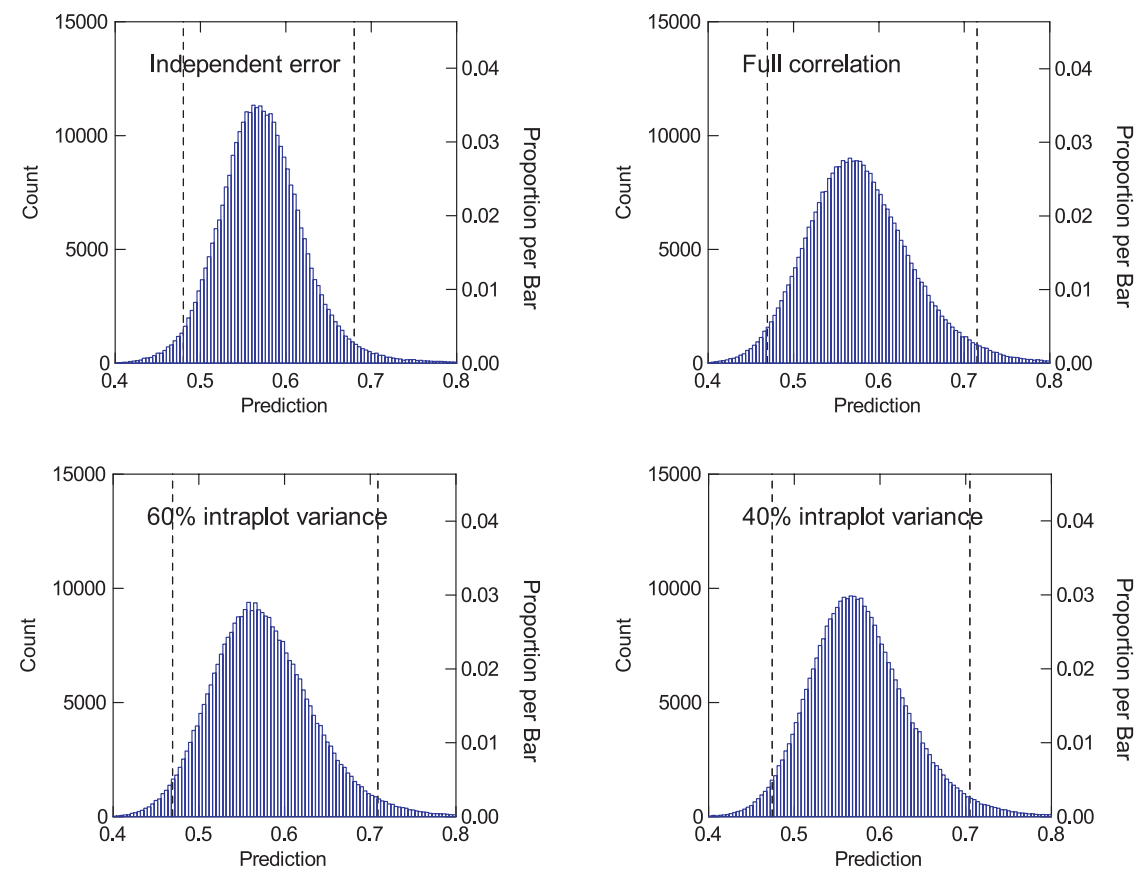

Figure 3. Probability density functions and $95 \%$ confidence intervals of $B E F$ values depending on the correlation of uncertainties with varying percentage of fixed intraplot variance, on $x$-axis the predicted $B E F$ and on $y$-axis the frequency of observations based on Monte Carlo simulations (according to Tab. IV).
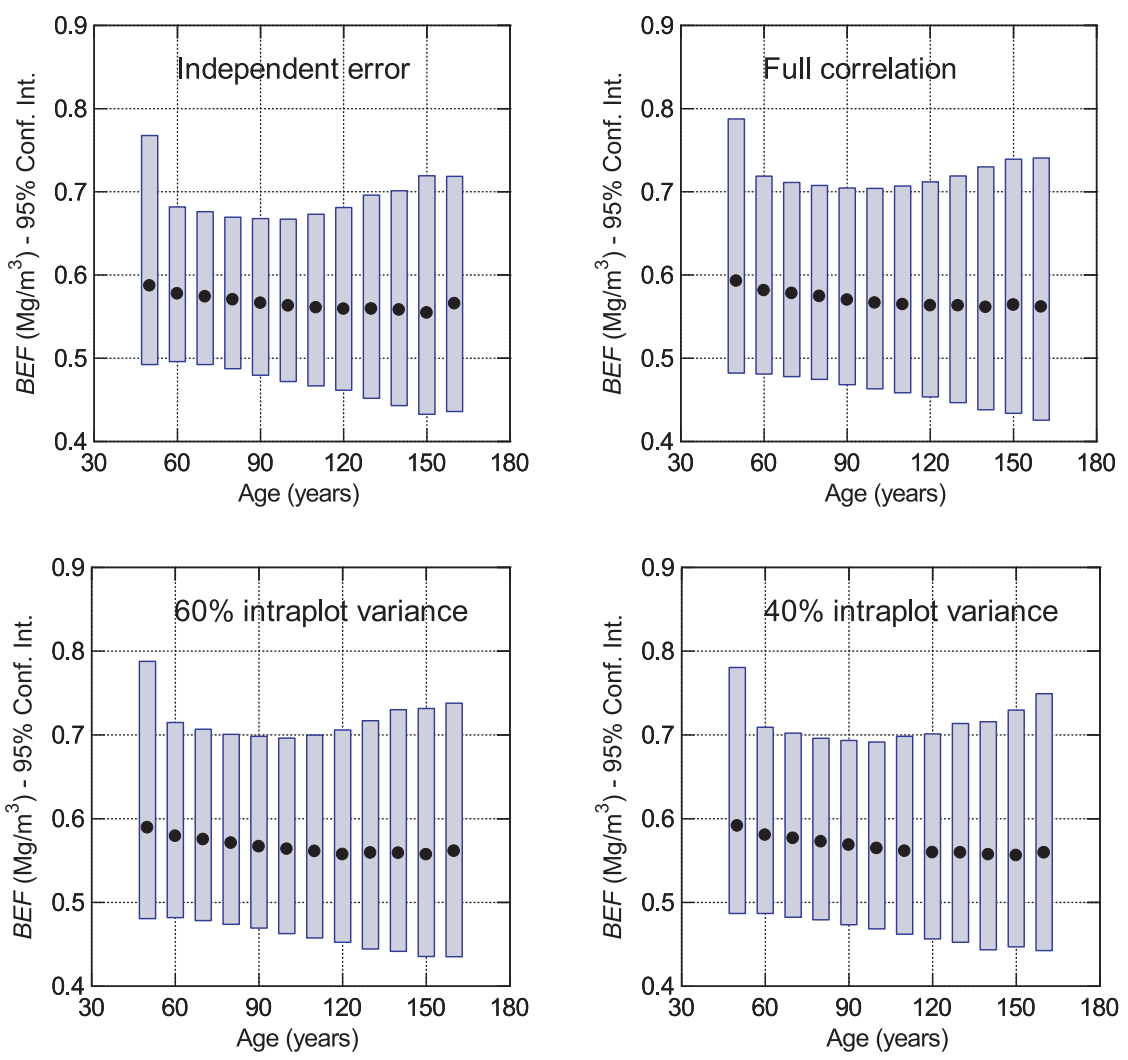

Figure 4. Medians and 95\% confidence intervals of $B E F$ values by age-classes with varying percentage of fixed intraplot variance (according to Tab. IV). 
Table V. Uncertainty estimates for BEFs (95\% confidence intervals) by age-classes for varying percentage of fixed intraplot variance (applied with residual errors of biomass- and volume models).

\begin{tabular}{|c|c|c|c|c|c|c|c|c|c|c|c|c|c|}
\hline $\begin{array}{l}\% \text { of fixed } \\
\text { intraplot variance }\end{array}$ & Age-class & -60 & $60-70$ & $70-80$ & $80-90$ & $90-100$ & $100-110$ & $110-120$ & $120-130$ & $130-140$ & $140-150$ & $\overline{150-160}$ & 160 \\
\hline 0 & $2.5 \%$ & 0.49 & 0.50 & 0.49 & 0.49 & 0.48 & 0.47 & 0.47 & 0.46 & 0.45 & 0.44 & 0.43 & 0.44 \\
\hline 0 & Median $B E F$ & 0.59 & 0.58 & 0.57 & 0.57 & 0.57 & 0.56 & 0.56 & 0.56 & 0.56 & 0.56 & 0.55 & 0.57 \\
\hline 0 & $97.5 \%$ & 0.77 & 0.68 & 0.68 & 0.67 & 0.67 & 0.67 & 0.67 & 0.68 & 0.70 & 0.70 & 0.72 & 0.72 \\
\hline 100 & $2.5 \%$ & 0.48 & 0.48 & 0.48 & 0.47 & 0.47 & 0.46 & 0.46 & 0.45 & 0.45 & 0.44 & 0.43 & 0.43 \\
\hline 100 & Median $B E F$ & 0.59 & 0.58 & 0.58 & 0.57 & 0.57 & 0.57 & 0.56 & 0.56 & 0.56 & 0.56 & 0.56 & 0.56 \\
\hline 100 & $97.5 \%$ & 0.79 & 0.72 & 0.71 & 0.71 & 0.70 & 0.70 & 0.71 & 0.71 & 0.72 & 0.73 & 0.74 & 0.74 \\
\hline 60 & $2.5 \%$ & 0.48 & 0.48 & 0.48 & 0.47 & 0.47 & 0.46 & 0.46 & 0.45 & 0.44 & 0.44 & 0.44 & 0.44 \\
\hline 60 & Median $B E F$ & 0.59 & 0.58 & 0.58 & 0.57 & 0.57 & 0.56 & 0.56 & 0.56 & 0.56 & 0.56 & 0.56 & 0.56 \\
\hline 60 & $97.5 \%$ & 0.79 & 0.71 & 0.71 & 0.70 & 0.70 & 0.70 & 0.70 & 0.71 & 0.72 & 0.73 & 0.73 & 0.74 \\
\hline 40 & $2.5 \%$ & 0.49 & 0.49 & 0.48 & 0.48 & 0.47 & 0.47 & 0.46 & 0.46 & 0.45 & 0.44 & 0.45 & 0.44 \\
\hline 40 & Median $B E F$ & 0.59 & 0.58 & 0.58 & 0.57 & 0.57 & 0.56 & 0.56 & 0.56 & 0.56 & 0.56 & 0.56 & 0.56 \\
\hline 40 & $97.5 \%$ & 0.78 & 0.71 & 0.70 & 0.70 & 0.69 & 0.69 & 0.70 & 0.70 & 0.71 & 0.72 & 0.73 & 0.75 \\
\hline
\end{tabular}
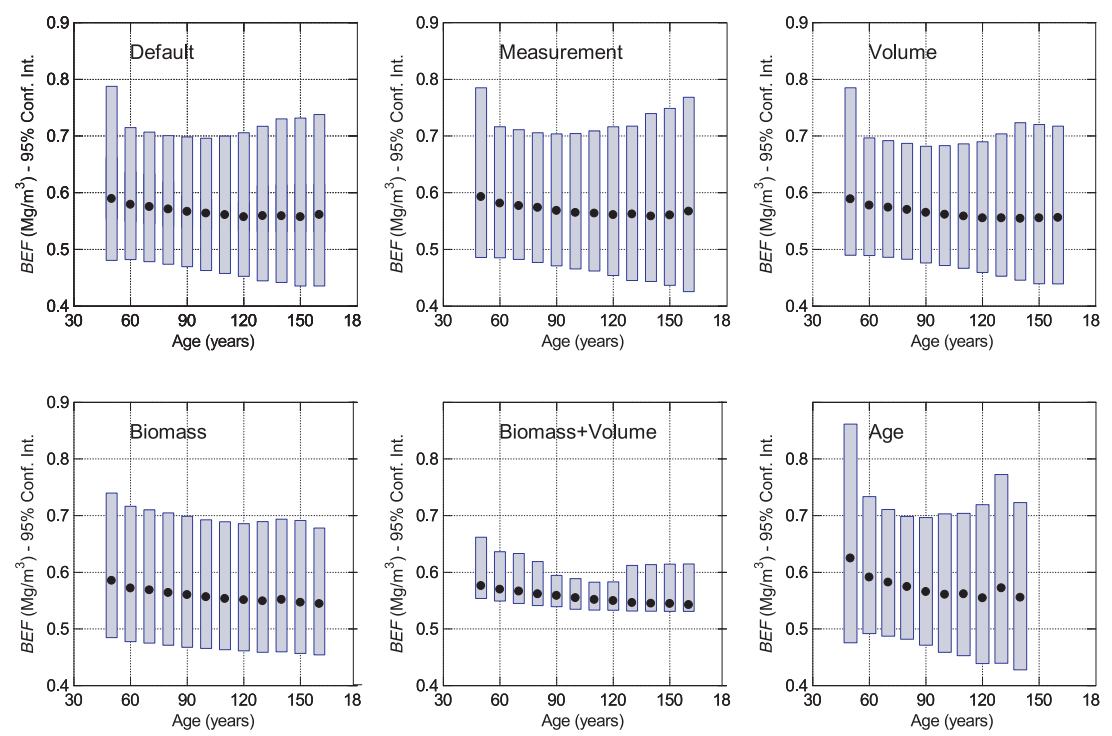

Figure 5. Impact of different sources of uncertainty on the overall uncertainty of BEFs, when $60 \%$ of the intraplot variance is fixed (residual errors of model predictions). In default, all sources of uncertainties are included. Thereafter, the following uncertainties were ignored separately: measurement errors $(D$ and $H$ ), volume model, biomass models, both volume and biomass models and stand age.

is also known that the biomass model errors and stem volume model errors correlate and that trees from same plot resemble each other [11]. Ignoring these mainly positive correlations when estimating the uncertainty in $B E F s$ will give error bounds that are too narrow (Figs. 4 and 5). Moreover, ignoring the model errors and especially the parameter uncertainty in the biomass models when the uncertainty in the $B E F$ is estimated gives error bounds that are too optimistic. This effect was most pronounced with younger and older age-classes, partly due to lower sample size (Figs. 4 and 5).

Lehtonen et al. [12] showed that the RSE of the BEF for Norway spruce varied between $3 \%$ and $21 \%$ by age-classes, while here the RSE (computed from probability distributions) varied between $7 \%$ and $15 \%$ for the independent errors and between $8 \%$ and $17 \%$ for the full correlation (Fig. 4). These studies differ in many aspects; e.g. Lehtonen et al. [12] excluded the uncertainty in stand age and also the parameter uncertainty of biomass models was lacking. Here the quantity of Norway spruce-dominated plots was 325, whereas in Finland it was 459; in addition tree height was also used as a predictor here. Despite the differences in the uncertainty analysis, both studies showed similar ranges of uncertainty, although with somewhat smaller RSEs for Finland compared with the uncertainties reported here.

For biomass estimation, uncertainty analysis is crucial but often difficult to conduct. In the optimal case, a representative sample of tree biomass covering the entire country could be used for determining the uncertainty in the $B E F$ (or biomass equations). Here, we were obliged to assume that some of the uncertainties, e.g. the model error for stem volume, were not available and therefore an $R S E$ of $10 \%$ was used. The lack of uncertainty estimates for the parameters of the volume models may lead to too optimistic an overall uncertainty in the $B E F$, especially when all the uncertainty in merchantable volume was treated as a residual error. On the other hand, the assumption of a $10 \% R S E$ was rather conservative, especially since Laasasenaho [10] reported prediction errors of $7.2 \%$ with a parameter uncertainty of less than $0.5 \%$ for typical dimension combinations for Scots pine in Finland. A potential bias associated with these $B E F$ values depends on selected biomass- 
and volume functions. The study of Wirth et al. [28] provides a solid basis for biomass estimation. It also includes a material of a Bohemian study by Černý [1] and the biomass equations may be rather safely assumed to be adequately representing tree allometry of Norway spruce located in Czech Republic. As for the volume equation applied [20], it was derived from a representative compilation of data used for volume tables in the former Czechoslovakia. Hence, both the biomass and volume equations applied here should result in an unbiased estimation of $B E F s$.

The uncertainty estimation of the $B E F s$ is essential when countries estimate the carbon stock changes in their forest biomass with $B E F s$, using the procedures of the IPCC [7]. The IPCC [7] showed that the carbon stock change of biomass can be estimated by comparing consecutive estimations of carbon stocks in national forest inventories (NFIs). If the uncertainty bounds of $B E F s$ are wide, the carbon stock change may not be statistically significant, especially if consecutive samples from the NFIs are not from the same plots, implying that the covariance term cannot be utilized for error propagation in the carbon stock change [26]. Additionally, the uncertainty estimation of $B E F s$ is frequently limited due to inadequate volume and biomass equations and their source material. To reduce the uncertainty in the estimate of carbon stock change of forest biomass, the reliability of the biomass and volume models must be improved, meaning that either more trees should be felled or that the already existing data should be more thoroughly used.

Acknowledgements: The authors acknowledge the support of the European Commission (CarboInvent; contract number EVK2-CT2002-00157) and of the Czech Ministry of Environment (CzechCARBO; VaV 640/18/03). We are also thankful to the Academy of Finland for financing the project 108328 and the visit of Dr. Emil Cienciala to Metla, Finland during 2005. We would also like to acknowledge Dr. Juha Lappi, Mr. Mikko Peltoniemi and three referees for giving valuable comments.

\section{REFERENCES}

[1] Černý M., Biomass of Picea abies (L.) Karst. in Midwestern Bohemia, Scand. J. For. Res. 5 (1990)

[2] CHMI, National greenhouse gas emission inventory report of the Czech Republic, NIR, (reported inventory 2003) (2005).

[3] Dean T.J., Cao Q.V., Inherent correlations between stand biomass variables calculated from tree measurements, For. Sci. 49 (2003) 279-284.

[4] Eid T., Use of uncertain inventory data in forestry scenario models and consequential incorrect harvest decisions, Silva Fenn. 34 (2000) 89-100.

[5] Fang J.-Y., Chen A., Peng C., Zhao S., Ci L., Changes in forest biomass carbon storage in China between 1949 and 1998, Science 292 (2001) 2320-2322.

[6] Heath L.S., Smith J.E., An assessment of uncertainty in forest carbon budget projections, Environ. Sci. Policy 3 (2000) 73-82.

[7] IPCC, Good practice guidance for land use, land-use change and forestry, IPCC National Greenhouse Gas Inventories Programme, 2003.

[8] Jalkanen A., Mäkipää R., Ståhl G., Lehtonen A., Petersson H., Estimation of biomass stock of trees in Sweden: comparison of biomass equations and age-dependent biomass expansion factors, Ann. For. Sci. 62 (2005) 845-851.

[9] Korhonen K.T., Maltamo M., Männyn maanpäällisten osien kuivamassat Etelä-Suomessa, Metsäntutkimuslaitoksen tiedonantoja 371 (1990) 1-29 + appendix $12 \mathrm{p}$.

[10] Laasasenaho J., Taper curve and volume functions for pine, spruce and birch, Comm. Inst. For. Fenn. 108 (1982) 1-74.

[11] Lappi J., Calibration of height and volume equations with random parameters, For. Sci. 37 (1991) 781-801.

[12] Lehtonen A., Mäkipää R., Heikkinen J., Sievänen R., Liski J., Biomass expansion factors $(B E F)$ for Scots pine, Norway spruce and birch according to stand age for boreal forests, For. Ecol. Manage. 188 (2004) 211-224.

[13] Levy P.E., Hale S.E., Nicoll B.C., Biomass expansion factors and root: shoot ratios for coniferous tree species in Great Britain, Forestry 77 (2004) 421-430.

[14] Löwe H., Seufert G., Raes F., Comparison of methods used within member states for estimating $\mathrm{CO} 2$ emissions and sinks according to UNFCCC and EU monitoring mechanism: forest and other wooded land, Biotechnol. Agron. Soc. Environ. 4 (2000) 315-319.

[15] Marklund L.G., Biomassafunktioner för tall, gran och björk i Sverige, Sveriges lantbruksuniversitet, Rapporter-Skog 45 (1988) $1-73$.

[16] McCulloch C.E., Searle S.R., Generalized, Linear and Mixed Models, John Wiley and Sons Ltd, New York, 2000.

[17] Monni S., Peltoniemi M., Palosuo T., Lehtonen A., Mäkipää R. Savolainen I., Uncertainty of forest carbon stock changes - implications to the total uncertainty of GHG inventory of Finland, Clim. Change (2007) (in press).

[18] Muukkonen P., Lehtonen A., Needle and branch biomass turnover rates of Norway spruce (Picea abies), Can. J. For. Res. 34 (2004) 2517-2527.

[19] Peltoniemi M., Palosuo T., Monni S., Mäkipää R., Factors affecting the uncertainty of sinks and stocks of carbon in Finnish forests soils and vegetation, For. Ecol. Manage. 232 (2006) 75-85.

[20] Petráš R., Pajtík J., Sústava Cesko-slovenských objemových tabuliek drevín (The set of Czecho-Slovakian volume tables of tree species), Lesnícky časopis 37 (1991) 49-56.

[21] SAS, SAS/STAT ${ }^{\circledR}$ User's Guide, Version 8, SAS Institute Inc., Cary, NC, USA., 1999.

[22] Satoo T., Madgwick H.A.I., Forest biomass, Martinus Nijhoff / Dr W. Junk Publisher, The Hague, 1982.

[23] Shvidenko A., Nilsson S., Dynamics of Russian forests and the carbon budget in 1961-1998: an assessment based on long-term forest inventory data, Clim. Change 55 (2002) 5-37.

[24] Smith J.E., Heath L.S., Identifying influences on model uncertainty: an application using a forest carbon budget model, Environ. Manage. 27 (2001) 253-267.

[25] Somogyi Z., Cienciala E., Mäkipää R., Lehtonen A., Muukkonen P., Weiss P., Indirect methods of large scale forest biomass estimation, Eur. J. For. Res. (2007) (in press).

[26] Ståhl G., Boström B., Lindkvist H., Lindroth A., Nilsson J., Olsson M., Methodological options for quantifying changes in carbon pools in Swedish forests, Stud. For. Suec. 214 (2004) 1-46.

[27] Vande Walle I., Van Camp N., Perrinc D., Lemeur R., Verheyen K., Van Wesemael B., Laitat E., Growing stock-based assessment of the carbon stock in the Belgian forest biomass, Ann. For. Sci. 62 (2005) 853-864.

[28] Wirth C., Schumacher J., Schulze E.D., Generic biomass functions for Norway spruce in Central Europe - a meta-analysis approach towards prediction and uncertainty estimation, Tree Phys. 24 (2004) $121-139$ 